\title{
BMJ Open Quality Reporting standards, outcomes and costs of quality improvement studies in Ireland: a scoping review
}

Siobhán Eithne McCarthy (D) , Samira Barbara Jabakhanji (D) ${ }^{2}$
Jennifer Martin (D), ${ }^{3}$ Maureen Alice Flynn (D), ${ }^{3}$ Jan Sørensen (D) ${ }^{2}$

\section{ABSTRACT}

Objectives To profile the aims and characteristics of quality improvement (QI) initiatives conducted in Ireland, to review the quality of their reporting and to assess outcomes and costs.

Design Scoping review.

Data sources Systematic searches were conducted in PubMed, Web of Science, Embase, Google Scholar, Lenus and rian.ie. Two researchers independently screened abstracts $(n=379)$ and separately reviewed 43 studies identified for inclusion using a 70 -item critique tool. The tool was based on the Quality Improvement Minimum Quality Criteria Set (QI-MQCS), an appraisal instrument for Ql intervention publications, and health economics reporting criteria. After reaching consensus, the final dataset was analysed using descriptive statistics. To support interpretations, findings were presented at a national stakeholder workshop.

Eligibility criteria QI studies implemented and evaluated in Ireland and published between January 2015 and April 2020.

Results The 43 studies represented various QI interventions. Most studies were peer-reviewed publications $(n=37)$, conducted in hospitals $(n=38)$. Studies mainly aimed to improve the 'effectiveness' (65\%), 'efficiency' (53\%), 'timeliness' (47\%) and 'safety' (44\%) of care. Fewer aimed to improve 'patient-centredness' (30\%), 'value for money' (23\%) or 'staff well-being' (9\%). No study aimed to increase 'equity'. Seventy per cent of studies described 14 of 16 QI-MQCS dimensions. Least often studies reported the 'penetration/reach' of an initiative and only $35 \%$ reported health outcomes. While $53 \%$ of studies expressed awareness of costs, only eight provided at least one quantifiable figure for costs or savings. No studies assessed the cost-effectiveness of the Ql.

Conclusion Irish Ql studies included in our review demonstrate varied aims and high reporting standards. Strategies are needed to support greater stimulation and dissemination of QI beyond the hospital sector and awareness of equity issues as QI work. Systematic measurement and reporting of costs and outcomes can be facilitated by integrating principles of health economics in Ql education and guidelines.

${ }^{3}$ National Quality Improvement Team, Health Service Executive, Dublin, Ireland

Correspondence to Dr Siobhán Eithne McCarthy; smccarthy@rcsi.ie patient experience and outcomes, better professional development and better system performance. ${ }^{1}$ Using clearly defined methodologies, the intention of QI is to make systematic, data-based, iterative improvements, to enhance healthcare delivery and outcomes. ${ }^{2}$ In 2001, the US Institute of Medicine (IOM) identified six goals of quality in healthcare: safety, timeliness, effectiveness, efficiency, equity and patient-centredness. ${ }^{3}$ Worldwide, organisations have followed these aspirations to chart QI plans. Due to the growing costs of healthcare globally, it is becoming increasingly obvious that the explicit aims of healthcare systems will no longer be to provide 'quality' exclusively, but to deliver 'value', that is quality relative to cost. ${ }^{4}$ To support the achievement of high-value healthcare, in 2008, the US Institute for Healthcare Improvement suggested health systems pursue the 'Triple Aim of Healthcare'; to improve the individual experience of care, improve the health of populations and reduce the per capita costs of care for populations. ${ }^{5}$ In recognition of the foundational role of staff well-being in achieving these aims, the improvement of the experience of providing care was added in 2014, to advocate the 'Quadruple Aim of Healthcare'. ${ }^{6}$

In Ireland and other countries, evidence is limited about the practice of QI and whether it supports better-value healthcare. ${ }^{7}$ Accordingly, only a fraction of QI projects implemented in practice are reported in peer-reviewed journals. ${ }^{8}$ There are some online QI reporting repositories to disseminate learning, however, variation in the classification of projects makes comparisons difficult. ${ }^{8}$ Furthermore, while the Standards for Quality Improvement Reporting Excellence guidelines advise to report costs, ${ }^{9}$ barriers to this include disparate and limited formal guidance for improvement teams on the measurement of costs associated with QI, 
and the accessibility of organisational and patient cost data. $^{710-15}$

To support effective decision-making, robust information is required about the content and context of QI initiatives, the expected outcomes, initial costs of implementation and the subsequent impact on longterm costs for the health service. ${ }^{10} 16$ Accordingly, several international reviews have identified the scope of QI practice $^{17}$ and good practice evaluation methods within different clinical areas. ${ }^{18-20}$ In Ireland, in recent years, QI has been strategically led and increasingly integrated in Irish health services. ${ }^{21}$ However to date, there has been no formal review of the characteristics and volume of Irish QI studies reported in the scientific literature. It is unclear how Irish QI studies align with recognised international quality goals ${ }^{3}$ and adhere to established reporting standards.

Therefore, this study aimed to map available reports of QI initiatives in Ireland and interpret their impact on patient experience, provider experience and health system performance. Specific objectives were to: (1) profile the aims and characteristics of QI initiatives conducted in Ireland, (2) review the quality of their methodological reporting and (3) assess the cost-effectiveness of the QI initiatives by comparing their outcomes and costs.

\section{METHODS}

A scoping review was performed according to the Johanna Biggs Institute, Guidance for Conducting Scoping Reviews. $^{22}$

\section{Search strategy}

We searched PubMed, Web of Science, Embase, Google Scholar and the two national databases Lenus and rian. ie for peer-reviewed articles and grey literature published from 1 January 2015 to 8 April 2020, using the search term "quality improvement", with the addition of ["Irish" OR "Ireland"] for international databases. The search was adjusted slightly for each database, given the differences in how their search tools are constructed (see online supplemental file 1 for details). Full texts were searched for cross-references of Irish QI studies that had not been retrieved through the original searches. Reports of QI initiatives known to the study team were included to maximise reach.

\section{Study selection}

All abstracts were reviewed independently by two researchers with a QI or health economic background. Inclusion criteria were that the study met the definition of QI (to support better patient experience/outcomes, professional development or system performance $)^{1}$ and was implemented and evaluated in the healthcare sector in Ireland. After the individual review of abstracts, both researchers discussed their assessment and formed consensus on inclusion for full-text review.

\section{Data abstraction and quality assessment}

Two researchers independently documented the reported characteristics, outcomes and costs of each QI study and assessed the study reporting standards using a novel 70-item assessment tool. To construct our tool, we used the Quality Improvement Minimum Quality Criteria Set (QI-MQCS) ${ }^{23}$ as a basis. The QI-MQCS enables reviewers of QI studies to report whether 16 QI reporting standards have been 'met', 'not met' or 'partially met'. ${ }^{23}$ We added measurement of the aims and characteristics of the QI studies. Namely, where appropriate, we added quantifiable study details to the QI-MQCS domains (9 of the 16). For example, we added each of the IOM goals of quality ${ }^{3}$ and the goals of 'staff well-being' and 'value for money' (binary 'yes'/'no' items) to the QI-MQCS domain of 'intervention description' to characterise study aims similarly to other review studies. ${ }^{1724}$ Furthermore, we incorporated basic tenets of health economic evaluation in our tool. ${ }^{10}$ We included items to assess reporting of various types of costs, the perspective (societal, healthcare services or public healthcare), costing approach (top-down, bottom-up or mixed), incremental analysis of cost and outcomes (cost-effectiveness and cost-utility analysis), discount rates of future costs/outcomes and the potential for sensitivity analysis. Finally, we added items assessing whether the QI had met its stated aims and had enhanced the patient experience, provider experience and system performance. For each study, we assessed whether it met each of the 16 QI-MQCS criteria and we recorded the additional quantifiable items detailed previously. No critical appraisal of methodological quality was conducted as this was not part of our study aims and is not standard for a scoping review. ${ }^{25}$ The tool was embedded in Microsoft Excel and was tested on 10 studies and extended following the initial use. An overview of the tool is provided in online supplemental file 2 .

Descriptive statistics were performed to profile the characteristics and reporting standard of QI initiatives. We held a stakeholder $(n=40)$ engagement workshop in October 2020 to share and contextualise the findings with invited national and international QI leaders: policymakers, practitioners, educators, health economists and patient and family representatives. This informed our discussion of the findings presented in this review.

\section{RESULTS}

\section{Data synthesis}

Of 379 references retrieved, 275 remained after removing duplicates. Eighty references were identified for full review, 43 of which satisfied the specified inclusion criteria, ${ }^{26-66}$ including two unpublished reports known to the authors. Search results and reasons for exclusion of studies are detailed in figure 1 . Of the 43 studies, the majority $(n=37 ; 86 \%)$ were peer-reviewed journal articles and the remainder $(n=6 ; 14 \%)$ formed grey literature. One in three journal articles featured in quality-themed journals and since January 2015, there is a trend towards 


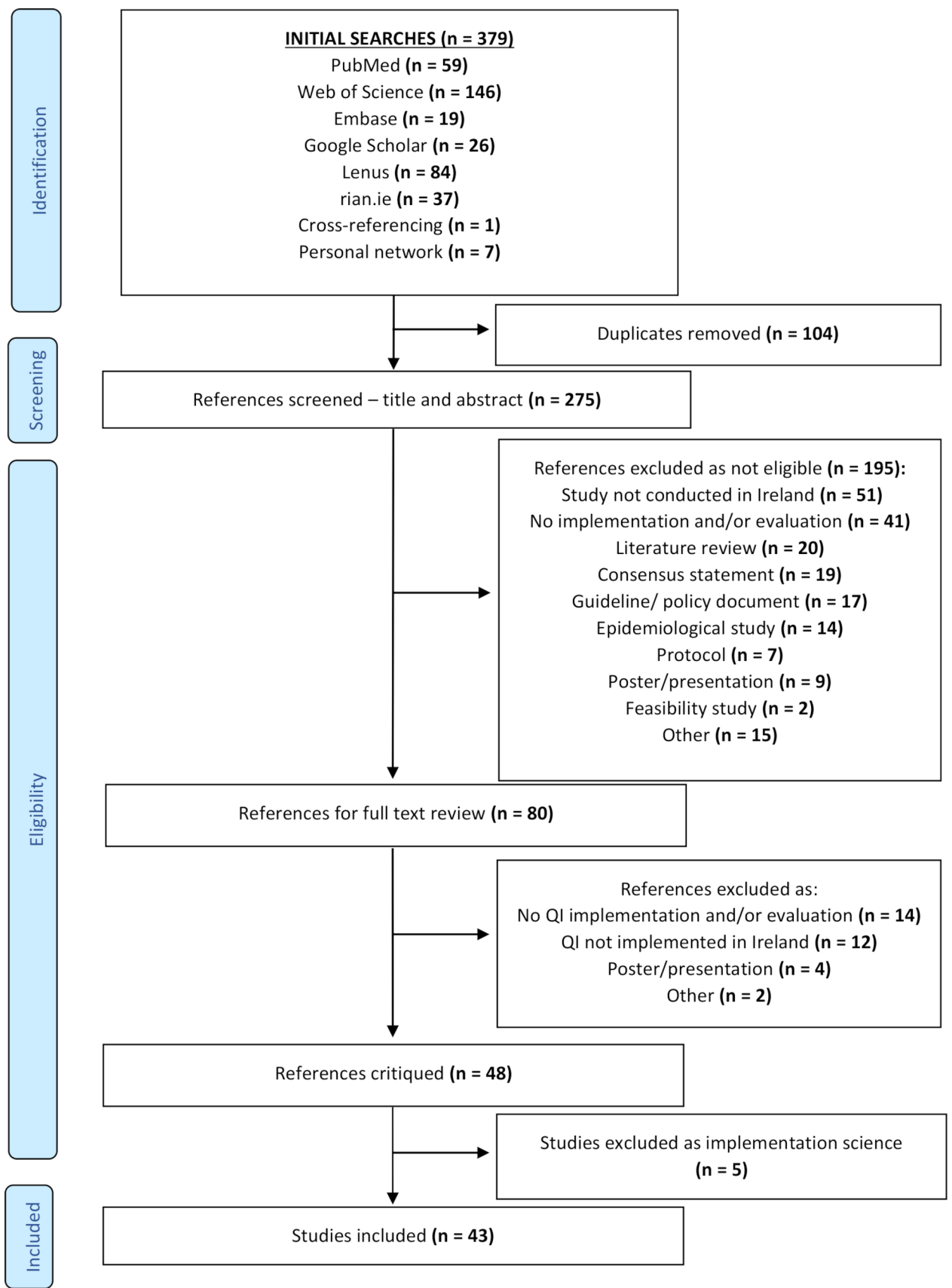

Figure 1 Study selection process. QI, quality improvement.

an increasing number of studies published each year (see details in online supplemental file 3 ).

\section{Reported characteristics of QI studies}

Ql location

Most studies ( $\mathrm{n}=33,77 \%)$ reported a QI implemented in a single organisational site. Fewer were implemented across organisations $(\mathrm{n}=7,16 \%)$ or at national or regional level $(n=3,7 \%)$. The majority of QIs were conducted in the hospital sector $(n=38,88 \%)$, mainly in acute hospitals $(\mathrm{n}=31,72 \%)$ (see details in online supplemental file $4)$. Most $(n=40,93 \%)$ did not mention whether healthcare services were public, private or mixed public-private institutions. On investigation of the institutional names reported in studies, we identified $89 \%$ as public, $2 \%$ as private and $2 \%$ as mixed public-private institutions. For the remaining $7 \%$, no information could be retrieved.

\section{QI aims and change ideas}

The 43 QI studies are characterised by study aim, methodology and design in table 1 and an extended description of the aims of studies is provided in online supplemental file 5 .

Most studies aimed to improve more than one domain of quality. Two in three studies aimed to improve the 'effectiveness' $(65 \%)$ of care while approximately half aimed to improve 'efficiency' (53\%), 'timeliness' (47\%) and 'safety' (44\%) (figure 2). Fewer aimed to improve 'patient-centredness' (30\%), 'value for money' (23\%) 
Table 1 Aim categorisation and key characteristics of QI studies

\begin{tabular}{|c|c|c|c|c|c|c|}
\hline QI study & $\begin{array}{l}\text { Aim } \\
\text { categorisation } \\
\text { (STEEEP-SV) }\end{array}$ & $\begin{array}{l}\text { QI } \\
\text { methodology }\end{array}$ & $\begin{array}{l}\text { QI study } \\
\text { design }\end{array}$ & $\begin{array}{l}\text { Study } \\
\text { time frame } \\
\text { (months) }\end{array}$ & $\begin{array}{l}\text { Health } \\
\text { outcomes } \\
\text { measured }\end{array}$ & $\begin{array}{l}\text { Cost } \\
\text { discussed } \\
\text { or } \\
\text { quantified }\end{array}$ \\
\hline Alexander et $\left.a\right|^{26}$ & $\mathrm{TE}_{2}$ & Lean & Pre-post & 15 & + & + \\
\hline Brown et $\mathrm{a}^{27}$ & $\mathrm{TE}_{1} \mathrm{E}_{2} \mathrm{~V}$ & LSS & Time series & 20 & + & + \\
\hline Clark et $\left.a\right|^{28}$ & $\mathrm{~S}_{1} \mathrm{TE}_{1} \mathrm{E}_{2} \mathrm{P}$ & - & Pre-post & 24 & + & + \\
\hline Collins and Hegarty ${ }^{29}$ & $\mathrm{SE}_{2}$ & LSS & Pre-post & - & - & + \\
\hline Conaty et $\left.a\right|^{30}$ & $\mathrm{~S}_{1} \mathrm{TE}_{1} \mathrm{E}_{2}$ & MFI PDSA & Time series & 8 & - & + \\
\hline Connor $^{31}$ & $E_{1} P$ & PDSA & Pre-post* & 12 & + & - \\
\hline Creed et $a^{32}$ & $\mathrm{E}_{2}$ & LSS DMAIC & Pre-post & 26 & - & + \\
\hline Davies et $a^{33}$ & $\mathrm{TE}_{2} \mathrm{PS}_{2} \mathrm{~V}$ & LSS DMAIC & Pre-post & 10 & - & + \\
\hline Dolan et $\left.a\right|^{34}$ & $\mathrm{P}$ & - & Pre-post & $12-24$ & - & + \\
\hline Dymond et $a /^{35}$ & $\mathrm{~S}_{1} \mathrm{TE}_{1}$ & - & Time series & 24 & - & - \\
\hline HSE QID 36 & $S$ & MFI PDSA & - & 40 & - & - \\
\hline HSE QID 37 & $S_{1} E_{1} P$ & MFI & Time series & 48 & + & + \\
\hline HSE QID 38 & $\mathrm{E}_{1}$ & MFI PDSA & Pre-post* & 12 & - & - \\
\hline HSE VIU (unpublished)† & $\mathrm{S}_{1} \mathrm{TE}_{1} \mathrm{E}_{2} \mathrm{~V}$ & PDSA & Time series & 24 & - & + \\
\hline Irwin et $\left.a\right|^{39}$ & $\mathrm{~S}_{1} \mathrm{E}_{1}$ & - & Pre-post & 4 & + & - \\
\hline Kieran et $a^{40}$ & $\mathrm{~S}_{1} \mathrm{E}_{2}$ & LSS & Pre-post & 16 & - & + \\
\hline Kilonzo et a $\left.\right|^{41}$ & $\mathrm{E}_{1} \mathrm{P}$ & - & Pre-post & 24 & + & - \\
\hline Lagan et al/2 & $\mathrm{TE}_{1} \mathrm{E}_{2} \mathrm{P}$ & PDSA & Pre-post* & 48 & - & + \\
\hline Linehan et $a l^{43}$ & $\mathrm{TE}_{1}$ & - & Pre-post & 36 & + & + \\
\hline McCarthy et al ${ }^{44}$ & $\mathrm{~S}_{1} \mathrm{E}_{1} \mathrm{E}_{2}$ & - & Time series & 18 & - & - \\
\hline McGlacken-Byrne et al ${ }^{45}$ & $S_{1} E_{1} P$ & PDSA & Time series & 2 & + & - \\
\hline McGrath et al ${ }^{46}$ & $\mathrm{TE}_{1} \mathrm{E}_{2}$ & PDSA & Time series & 18 & + & + \\
\hline McGrath et al ${ }^{47}$ & $\mathrm{TE}_{1} \mathrm{E}_{2} \mathrm{~S}_{2}$ & LSS & Pre-post & 12 & - & + \\
\hline McNamara et $a l^{48}$ & $S_{1} E_{1} V$ & MFI PDSA & Pre-post* & 12 & - & + \\
\hline Medani et $a{ }^{49}$ & $\mathrm{E}_{1}$ & - & Pre-post & 6 & - & - \\
\hline Meehan et $\left.a\right|^{50}$ & $\mathrm{~S}_{1} \mathrm{TE}_{2} \mathrm{~V}$ & - & Post-only & 12 & + & + \\
\hline Moran et $a^{51}$ & $\mathrm{E}_{2} \mathrm{~V}$ & - & PCG & 4 & - & + \\
\hline Moran et $a^{52}$ & $\mathrm{~S}_{1}$ & PDSA & Pre-post* & 7 & - & - \\
\hline Murphy et $\left.a\right|^{53}$ & $\mathrm{TE}_{2} \mathrm{P}$ & MFI PDSA & Time series & 18 & - & - \\
\hline Murray et $a l^{54}$ & $E_{1}$ & PDSA & Pre-post & 18 & - & - \\
\hline O’Hanlon et a $\left.\right|^{55}$ & $\mathrm{~S}_{1} \mathrm{TE}_{1}$ & PDSA & Pre-post* & 21 & + & - \\
\hline O'Reilly et $a^{56}$ & $\mathrm{~S}_{1} \mathrm{TE}_{1} \mathrm{E}_{2} \mathrm{~V}$ & - & Time series & - & - & + \\
\hline Osuafor et a $\left.\right|^{57}$ & $\mathrm{E}_{1} \mathrm{P}$ & PDSA & Pre-post & - & + & - \\
\hline Owen et $a^{58}$ & $\mathrm{~S}_{1} \mathrm{E}_{1} \mathrm{E}_{2}$ & - & Pre-post & 3 & - & - \\
\hline Owens et $\left.a\right|^{59}$ & $\mathrm{~S}_{1} \mathrm{TE}_{1}$ & - & Pre-post & 1.1 & - & - \\
\hline Riordan et $a^{60}$ & $\mathrm{E}_{1}$ & - & Time series & $12 \times 4$ & + & - \\
\hline Ryan et al ${ }^{61}$ & $\mathrm{TE}_{2} \mathrm{~V}$ & LSS & Pre-post* & 22 & - & + \\
\hline Stewart et a/ ${ }^{62}$ & $E_{1} P$ & $\mathrm{AR}$ & $\mathrm{PCG}^{*}$ & 10 & - & - \\
\hline Tangney (unpublished) $\ddagger$ & $\mathrm{E}_{1} \mathrm{E}_{2} \mathrm{PV}$ & - & Pre-post & 24 & - & + \\
\hline Teeling et $\mathrm{a} \mathrm{f}^{63}$ & $\mathrm{TE}_{1} \mathrm{E}_{2} \mathrm{P}$ & LSS PDSA & Pre-post & 6 & + & + \\
\hline Ullah et al ${ }^{64}$ & $\mathrm{TE}_{2}$ & Lean & Pre-post & 7 & - & + \\
\hline White et $a /^{65}$ & $\mathrm{TE}_{2} \mathrm{PS}_{2}$ & Lean & $\mathrm{PCG}^{*}$ & 15 & - & - \\
\hline
\end{tabular}


Table 1 Continued

\begin{tabular}{|c|c|c|c|c|c|c|}
\hline Ql study & $\begin{array}{l}\text { Aim } \\
\text { categorisation } \\
\text { (STEEEP-SV) }\end{array}$ & $\begin{array}{l}\text { QI } \\
\text { methodology }\end{array}$ & $\begin{array}{l}\text { Ql study } \\
\text { design }\end{array}$ & $\begin{array}{l}\text { Study } \\
\text { time frame } \\
\text { (months) }\end{array}$ & $\begin{array}{l}\text { Health } \\
\text { outcomes } \\
\text { measured }\end{array}$ & $\begin{array}{l}\text { Cost } \\
\text { discussed } \\
\text { or } \\
\text { quantified }\end{array}$ \\
\hline
\end{tabular}

'+' indicates reported; '-' indicates not reported.

*Includes time series data.

†HSE Value Improvement Unit. An evaluation of the collaborative project with RCSI on the development of a Theatre Quality Improvement Programme (TQIP) and the Integrated Care Programme for Patient Flow, Clinical Strategy and Programmes Division (CPSD). Ireland: HSE; 2019.

‡Tangney K. Theatre Quality Improvement Programme. End of Year (2018) Evaluation Report. Ireland: RCSI; 2019.

AR, Action Research; DMAIC, Define Measure Analyse Improve Control; $E_{1}$, effectiveness; $E_{2}$, efficiency; $E_{3}$, equity; LSS, Lean Six Sigma; MFI, Model for Improvement; P, patient-centredness; PCG, parallel control group; PDSA, Plan-Do-Study-Act; QI, quality improvement; ${ }_{1}$, safety; $\mathrm{S}_{2}$, staff well-being; $\mathrm{T}$, timeliness; $\mathrm{V}$, value for money.

or 'staff well-being' $(9 \%)$. No study aimed to increase 'equity' of care provision.

The 43 studies also reported on a variety of themes for QI change ideas, with little overlap across studies. Noteworthy themes included testing the effect of technology, ${ }^{28} 295061$ time to care, ${ }^{32} 3365$ health surveillance, ${ }^{42} 434547$ education ${ }^{48} 495859$ and antimicrobial use $^{304455}$ interventions on healthcare quality.

\section{QI methodology}

Two-thirds of studies $(65 \%, \mathrm{n}=28)$ reported the use of an established QI method. Of these, approximately half $(n=15)$ used the 'Plan-Do-Study-Act Cycle' ( $n=9)$ or 'Model for Improvement' $(\mathrm{n}=6), 12$ used a form of Lean ('Lean Six Sigma, Define Measure Analyse Improve Control' ( $n=6)$; 'Lean Six Sigma' ( $\mathrm{n}=2$ ) or 'Lean' $(\mathrm{n}=4)$ ) and one study used Action Research (table 1). While 15 studies did not report the use of a formal QI method, the authors, however, labelled these studies as 'QI' and reported the use of common QI practices. For example, the utilisation of quality tools to diagnose, measure and enhance quality.

\section{QI study designs and data sources}

Nearly all studies $(97 \%, \mathrm{n}=42)$ named the study design (table 1). The majority $(\mathrm{n}=26,62 \%)$ were pre-post designs; studies that compared the same parameters before and after QI implementation. Of these, six (23\%) also collected time series data to track iterative changes. A further one-quarter of studies, without establishing prepost measures, collected time series data to track iterative change $(\mathrm{n}=11,26 \%)$. The remaining studies collected post implementation data only $(n=1,2 \%)$ or used parallel control group designs $(n=4,10 \%)$. Furthermore, the majority of studies described the existing standard of care before implementation of the QI intervention (the 'comparator'; $\mathrm{n}=36,84 \%$ ) and mechanisms for 'fidelity

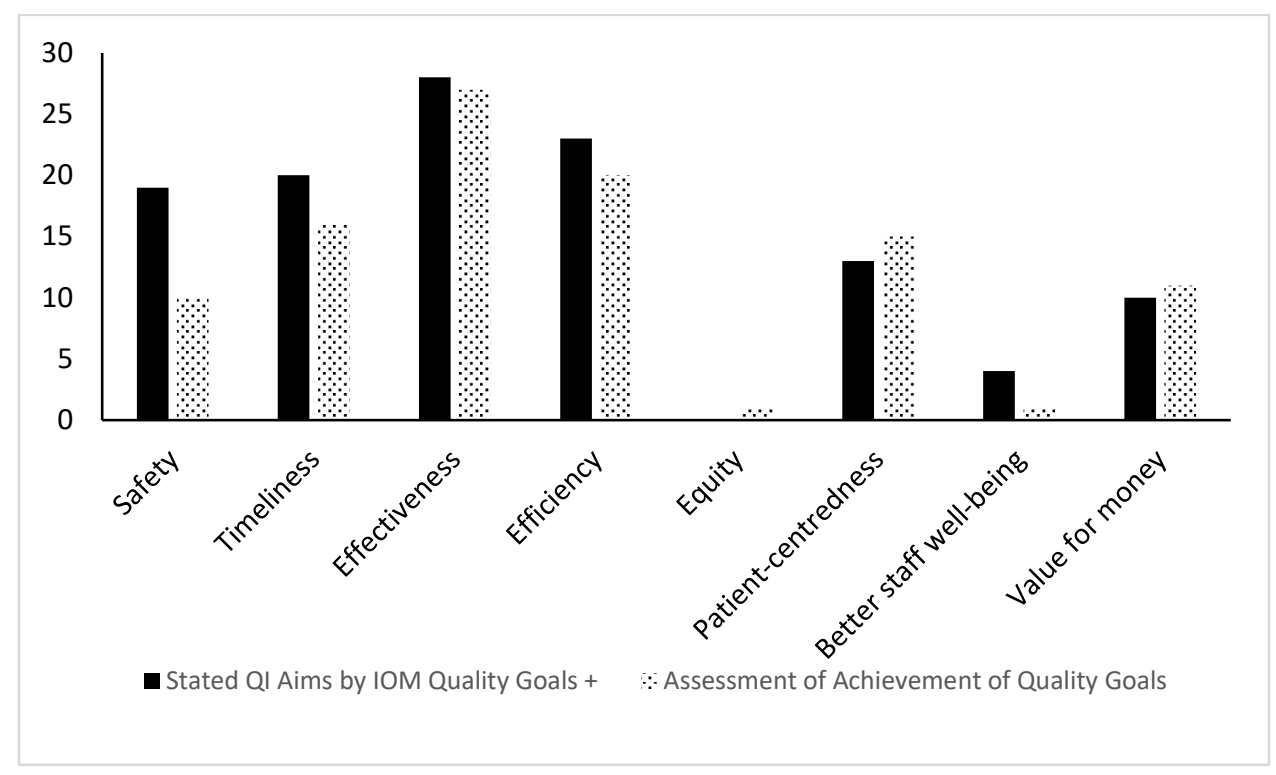

Figure 2 Number of quality improvement (QI) studies which aimed to enhance Institute of Medicine (IOM) quality goals ${ }^{+}$and frequency of studies that indicated achievement of these goals. 
and adherence' $(n=36,84 \%)$, such as compliance with intervention components.

Most studies $(\mathrm{n}=28,65 \%)$ used routine healthcare data (eg, patient records, prescriptions charts) solely $(n=11)$ or in conjunction with other data sources $(n=17)$. In $70 \%$ of studies $(n=30)$, non-routine data were collected. Through use of surveys or interviews, approximately one in four studies $(n=11)$ incorporated patients' views, one in five $(n=9)$ incorporated staff views and few incorporated relatives' or carers' views $(n=3,2 \%)$. Data collection mainly focused on care processes and one in three studies $(\mathrm{n}=15,35 \%)$ reported on health outcomes.

\section{Ql study time frame}

Study time frames varied across the 40 studies reporting this detail (table 1). The average total study duration was 16.8 months, the minimum 1 month and the maximum 48 months. Fewer studies $(n=29,67 \%)$ reported the duration of the QI implementation, which was 8.7 months on average, 1 week at a minimum and maximum 24 months.

\section{Health outcomes}

Fifteen studies $(35 \%)$ reported patient health outcomes $(28 \%)$, for example, pain or infection, or proxies for patient health outcomes $(7 \%)$, for example, length of stay or hospital admission rate (table 1). Studies reported that health outcomes were positively affected by the QI. No study examined health outcomes for staff.

\section{QI costs}

As displayed in table 1, 23 studies (53\%) discussed or alluded to costs associated with the QI initiative. Tangney and seven other studies $28323751566163(\mathrm{n}=8,19 \%)$, provided at least one quantifiable figure for a cost or cost saving. As shown in table 2, the 23 studies mostly considered 'staff costs' (57\%), followed by 'overhead costs' (39\%), 'capital costs' (35\%) and 'indirect healthcare costs' (22\%). A single study included 'direct costs to the healthcare user'. Five studies $(22 \%)$ did not break down the types of costs considered.

An example of detailed cost data was provided in one study $^{28}$ that compared the cost of staff and phone/texting charges before and after implementation, and mentioned two technology purchases for implementation; while a full cost analysis, details on the perspective (healthcare/ public health/societal), costing approach (top-down or bottom-up) or incremental analysis was not provided. Considering all 43 studies, performing a full economic assessment is not possible based on the data reported.

\section{Achievement of QI aims}

Ninety-eight per cent of studies were interpreted by the researchers to have achieved their intended aims, either fully $(70 \%)$ or partially $(28 \%)$. These studies most frequently conveyed 'effectiveness' (64\%), 'efficiency' (48\%), 'timeliness' (38\%) and 'person-centredness' $(36 \%)$ as the elements of healthcare quality improved. Furthermore, one in four studies conveyed improved 'safety' $(n=10)$ and 'value for money' $(n=11)$. Few reported improvements to 'staff well-being' (2\%) and the 'equity' (2\%) domain (figure 2 ).

\section{Sustainability and spread of QI initiatives}

Over $90 \%$ of studies reported on the sustainability of the QI. Specifically, $88 \%$ of studies $(n=38)$ reported evidence of enduring improvement and $60 \% \quad(n=26)$ reported policy changes implemented or needed to support the change. The spread or the requirements for spread were discussed in $86 \%$ of studies $(n=37)$.

\section{Assessment of Ql impact}

Over $90 \%$ of studies were interpreted to have improved the system performance $(91 \%)$. Less were interpreted to have improved the patient experience $(n=28,65 \%)$ and provider experience $(n=20,47 \%)$.

\section{Assessment of the reporting standard of QI studies}

Seventy per cent of studies $(n=30)$ met the minimum standard for reporting 14 of 16 QI criteria (either fully or partially) as described by the QI-MQCS ${ }^{23}$ (table 3).

Studies least often reported the 'penetration/reach' $(53 \%)$ of an initiative such as the number of units or sites participating in the intervention compared with those available or eligible and 'health outcomes' (35\%) such as health-related outcomes of patients or non-professional carers.

\section{DISCUSSION}

An increasing number of QI studies in the Irish Health Service were published over the past 5 years, most of which focused on improving the effectiveness, efficiency, timeliness and safety of care. Most of the studies were single-site hospital-based projects focused on 'better disease management'. This phenomenon has recently been termed as Quality 2.0, an advancement on the field's historical focus on compliance to minimum standards, Quality 1.0. ${ }^{67}$ Examples from our review included initiatives to reduce adverse events, to increase capacity and to

\begin{tabular}{|c|c|c|c|c|c|c|c|}
\hline & Staff costs & $\begin{array}{l}\text { Overhead } \\
\text { costs }\end{array}$ & $\begin{array}{l}\text { Capital } \\
\text { costs }\end{array}$ & $\begin{array}{l}\text { Direct costs to } \\
\text { healthcare user }\end{array}$ & $\begin{array}{l}\text { Indirect } \\
\text { costs }\end{array}$ & $\begin{array}{l}\text { General } \\
\text { costs }\end{array}$ & $\begin{array}{l}\text { Sensitivity } \\
\text { analysis }\end{array}$ \\
\hline $\begin{array}{l}\text { Discussed and } \\
\text { quantified }\end{array}$ & 4 & 3 & 2 & 0 & 1 & 1 & 0 \\
\hline
\end{tabular}


Table 3 Number and percentage of studies that met reporting standards of the Quality Improvement Minimum Quality Criteria Set

\begin{tabular}{|c|c|c|c|}
\hline & $\begin{array}{l}\text { Met } \\
\mathbf{N}(\%)\end{array}$ & $\begin{array}{l}\text { Partially } \\
\text { met } \\
\text { N (\%) }\end{array}$ & $\begin{array}{l}\text { Not met } \\
\mathbf{N}(\%)\end{array}$ \\
\hline Organisational motivation & $42(98)$ & 0 & $1(2)$ \\
\hline Intervention rationale & $43(100)$ & 0 & 0 \\
\hline Intervention description & $43(100)$ & 0 & 0 \\
\hline $\begin{array}{l}\text { Organisational } \\
\text { characteristics }\end{array}$ & $39(91)$ & $4(9)$ & 0 \\
\hline Implementation & 40 (93) & 0 & $3(7)$ \\
\hline Study design & $42(98)$ & $1(2)$ & 0 \\
\hline Comparator & $35(82)$ & $1(2)$ & $7(16)$ \\
\hline Data source & $41(95)$ & $2(5)$ & 0 \\
\hline Timing & $34(79)$ & $7(16)$ & $2(5)$ \\
\hline Adherence/fidelity & $34(79)$ & $2(5)$ & $7(16)$ \\
\hline Health outcomes & $15(35)$ & 0 & $28(65)$ \\
\hline Organisational readiness & $30(70)$ & 0 & $13(30)$ \\
\hline Penetration/reach & $21(49)$ & $2(5)$ & $20(46)$ \\
\hline Sustainability & $39(91)$ & 0 & $4(9)$ \\
\hline Spread & $35(81)$ & $2(5)$ & $6(14)$ \\
\hline Limitation(s) & $30(70)$ & $1(2)$ & $12(28)$ \\
\hline
\end{tabular}

release time to care. While our review found that patientcentredness, staff well-being and value for money were less often the focus of improvements, the equity dimension of quality was not a focus at all. Recent research has indicated that standards to help organisations monitor and improve their ability to provide equitable care are less mainstream than other quality standards ${ }^{24}$ and are at pilot stage in numerous countries. ${ }^{68}$

All studies shared important learning. Our assessment that over $90 \%$ of studies achieved their aims (fully or partially) and improved the health system performance presents a good indicator of the impact of QI approaches taken. Studies demonstrated very good coverage of international minimum standards for QI reporting across 14 of 16 criteria. $^{23}$ Similar to other review studies, ${ }^{19}$ we identified opportunities for improvement in relation the "penetration/reach" of the initiative.

Our study also identified that the health outcomes and costs of QIs were understudied. Only one in three studies reported health outcomes. While $53 \%$ of studies discussed or quantified costs, it was not feasible to ascertain the cost-effectiveness of QI initiatives due to limited measurement of health outcomes and absence of comprehensive cost data. Other studies have similarly found that the costs of staff time and of ongoing data monitoring are often poorly elucidated in improvement work. ${ }^{19}$ Yet, as over half of studies discussed costs without adequately quantifying them, our findings suggest that knowledge of, or confidence in, performing cost assessments may be low among individuals engaged in QI.

In the context of the Quadruple Aim of Healthcare, ${ }^{6}$ together, these findings indicate that the QI studies were often focused on enhancing the quality of care patients receive and less often on measuring associated changes in health outcomes, costs, or staff well-being.

\section{Implications}

The profile of studies in our review implies there is strong engagement in QI project work in local settings yet insufficient measurement of cost and outcomes. Reflecting stakeholder discussions, adopting a value-based approach to programmes of $\mathrm{QI}^{69-72}$ may support large-scale service enhancement and better health (Quality 3.0). ${ }^{67}$ Clear guidelines exist for the assessment of resource use and cost in QI studies ${ }^{10-14}$ and in healthcare more generally. ${ }^{73-76}$ These should be further explored and tailored to support documentation and reporting of costs in QI. The development of QI reporting checklists that include explicit health economic items would also be of benefit.

Additionally, adopting equity standards for healthcare in the future, may support greater awareness of equity issues, and foster equity measures and improvements. ${ }^{68}$ Routine data collection on outcomes and costs is important to assure that health gains in one subpopulation are not achieved at the expense of another. ${ }^{5}$ Further, to support policies aimed at integrating care in the community in Ireland, ${ }^{77}$ increased visibility of QI work beyond the acute sector is needed.

Finally, for QI practitioners, this scoping review may help inform QI practice and reporting. A systematic review of QI studies in specific clinical contexts could follow on to identify best practices in these areas.

\section{Strengths and limitations}

To our knowledge, this is the first study to profile QI studies focused on a range of $\mathrm{QI}$ interventions on a country level. A key strength was that we used a robust scoping review approach and published critique tool adapted to context. Our use of two researchers to independently screen abstracts, review QI studies and build consensus reduces the potential for bias in our findings. Our workshop with QI stakeholders helped with interpretation and contextualisation of the findings. Yet, as our review was based on QI studies in the public domain, the results may not give a full representation of QI work conducted in Ireland over the past 5 years. Therefore, for non-acute sectors, it is difficult to conclude what activities are needed most: stimulus to support QI work or increased support for dissemination activities. Publication bias may have led to a proportionally higher level of QI studies of high reporting standard. Additionally, our study results likely reflect to some extent self-reporting bias in QI studies. However, our rigorous approach to the interpretation of results may have off-set this somewhat. 


\section{CONCLUSION}

Studies included in our review demonstrated a variety of QI interventions and high reporting standards. Strategies are needed to support stimulation and dissemination of QI beyond the acute sector and awareness of equity issues as QI work. While it was not possible to assess the costeffectiveness of QI interventions, it is clear that QI practitioners need to consider and report health outcomes and costs, routinely. This achievable goal may better support decision-making about resource allocation to maximise healthcare quality and health outcomes.

Twitter Siobhán Eithne McCarthy @SiobhanMCarthy and Samira Barbara Jabakhanji @SamiraJabakhanj

Acknowledgements Dr Philip Crowley, National Director for Quality Improvement, Health Service Executive for commissioning the review and supporting the process. Gethin White, HSE Librarian for advice on search process. Workshop participants. Dr Peter Lachman, International Society for Quality in Healthcare and Ray Healy, Department of Health for contributing their perspective.

Contributors Idea for research: JS, JM. Research design: SMC, SBJ, JS, JM, MAF. Tool development, search and critique: SMC, SBJ. Descriptive statistics and inclusion of manuscript references: SMC. Plan and deliver national stakeholder engagement workshop: MAF, JM, SMC, SBJ, JS. Manuscript development: SMC, SBJ and JS. Manuscript edits: JM, MAF. All authors have approved the submitted version of the paper.

Funding This study was supported by HSE National Quality Improvement Team.

Competing interests None declared.

Patient consent for publication Not required.

Provenance and peer review Not commissioned; externally peer reviewed.

Supplemental material This content has been supplied by the author(s). It has not been vetted by BMJ Publishing Group Limited (BMJ) and may not have been peer-reviewed. Any opinions or recommendations discussed are solely those of the author(s) and are not endorsed by BMJ. BMJ disclaims all liability and responsibility arising from any reliance placed on the content. Where the content includes any translated material, BMJ does not warrant the accuracy and reliability of the translations (including but not limited to local regulations, clinical guidelines, terminology, drug names and drug dosages), and is not responsible for any error and/or omissions arising from translation and adaptation or otherwise.

Open access This is an open access article distributed in accordance with the Creative Commons Attribution Non Commercial (CC BY-NC 4.0) license, which permits others to distribute, remix, adapt, build upon this work non-commercially, and license their derivative works on different terms, provided the original work is properly cited, appropriate credit is given, any changes made indicated, and the use is non-commercial. See: http://creativecommons.org/licenses/by-nc/4.0/.

\section{ORCID iDs}

Siobhán Eithne McCarthy http://orcid.org/0000-0001-5651-2409

Samira Barbara Jabakhanji http://orcid.org/0000-0002-4870-9110

Jennifer Martin http://orcid.org/0000-0002-4188-8136

Maureen Alice Flynn http://orcid.org/0000-0001-5837-8936

Jan Sørensen http://orcid.org/0000-0003-0857-9267

\section{REFERENCES}

1 Batalden PB, Davidoff F. What is "quality improvement" and how can it transform healthcare? Qual Saf Health Care 2007;16:2-3.

2 Lynn J, Baily MA, Bottrell M, et al. The ethics of using quality improvement methods in health care. Ann Intern Med 2007;146:666-73.

3 Institute of Medicine Committee on Quality of Health Care in America. Crossing the quality chasm: a new health system for the 21st century. Washington, DC: National Academies Press (US), 2001.

4 Wachter RM, Gupta K. Safety, quality, and value. understanding patient safety. 3e. New York, NY: McGraw-Hill Education, 2017.

5 Berwick DM, Nolan TW, Whittington J. The triple aim: care, health, and cost. Health Aff 2008;27:759-69.
6 Bodenheimer T, Sinsky C. From triple to quadruple aim: care of the patient requires care of the provider. Ann Fam Med 2014;12:573-6.

7 Brown SES, Chin MH, Huang ES. Estimating costs of quality improvement for outpatient healthcare organisations: a practical methodology. Qual Saf Health Care 2007;16:248-51.

8 Bytautas JP, Gheihman G, Dobrow MJ. A scoping review of online repositories of quality improvement projects, interventions and initiatives in healthcare. BMJ Qual Saf 2017;26:296-303.

9 Ogrinc G, Davies L, Goodman D, et al. SQUIRE 2.0 (standards for quality improvement reporting excellence): revised publication guidelines from a detailed consensus process. BMJ Qual Saf 2016;25:986-92.

10 Severens JL. Value for money of changing healthcare services? Economic evaluation of quality improvement. Qual Saf Health Care 2003;12:366-71.

11 Thompson C, Pulleyblank R, Parrott S, et al. The cost-effectiveness of quality improvement projects: a conceptual framework, checklist and online tool for considering the costs and consequences of implementation-based quality improvement. J Eval Clin Pract 2016;22:26-30.

12 Shah A, Course S. Building the business case for quality improvement: a framework for evaluating return on investment. Future Healthc J 2018;5:132-7.

13 Fischer HR, Duncan SD. The business case for quality improvement. J Perinatol 2020;40:972-9.

14 Mendlowitz A, Croxford R, MacLagan L, et al. Usage of primary and administrative data to measure the economic impact of quality improvement projects. BMJ Open Qual 2020;9:e000712.

15 Shaikh U, Lachman P, Padovani AJ, et al. The care and keeping of clinicians in quality improvement. Int $J$ Qual Health Care 2020;32:480-5.

16 Broughton El, Marquez L. Why economic analysis of health system improvement interventions matters. Front Public Health 2016;4:218.

17 White DE, Straus SE, Stelfox HT, et al. What is the value and impact of quality and safety teams? A scoping review. Implement Sci 2011;6:97.

18 Gorski I, Bram JT, Sutermaster S, et al. Value propositions of mHealth projects. J Med Eng Technol 2016;40:400-21.

19 Roberts SLE, Healey A, Sevdalis N. Use of health economic evaluation in the implementation and improvement science fields-a systematic literature review. Implement Sci 2019;14:72.

20 Nuckols TK, Keeler E, Morton S, et al. Economic evaluation of quality improvement interventions designed to prevent Hospital readmission: a systematic review and meta-analysis. JAMA Intern Med 2017;177:975-85.

21 Health Service Executive National Quality Improvement Team. By all, with all, for all: a strategic approach to improving quality 2020-2024, 2020. Available: https://www.hse.ie/eng/about/who/qid/strategicplan-2019-2024/ [Accessed 7 Dec 2020].

22 Peters MDJ, Godfrey CM, Khalil H, et al. Guidance for conducting systematic scoping reviews. Int J Evid Based Healthc 2015;13:141-6.

23 Hempel S, Shekelle PG, Liu JL, et al. Development of the quality improvement minimum quality criteria set (QI-MQCS): a tool for critical appraisal of quality improvement intervention publications. BMJ Qual Saf 2015;24:796-804.

24 Araujo CAS, Siqueira MM, Malik AM. Hospital accreditation impact on healthcare quality dimensions: a systematic review. Int J Qual Health Care 2020;32:531-44.

25 Munn Z, Peters MDJ, Stern C, et al. Systematic review or scoping review? guidance for authors when choosing between a systematic or scoping review approach. BMC Med Res Methodol 2018;18:1-7.

26 Alexander L, Moore S, Salter N, et al. Lean management in a liaison psychiatry department: implementation, benefits and pitfalls. BJPsych Bull 2020;44:18-25.

27 Brown R, Grehan P, Brennan M, et al. Using lean six sigma to improve rates of day of surgery admission in a national thoracic surgery department. Int J Qual Health Care 2019;31:14-21.

28 Clark A, Deverell D, Corcoran E, et al. Finger prick to finger tip: use of mobile phone technology to send PKU blood results. J Nutr Metab 2018;2018:2178346.

29 Collins K, Hegarty B. Electronic General GP radiology referrals: case study: EHealth, 2015. Available: lenus.ie/handle/10147/596904 [Accessed 7 Dec 2020].

30 Conaty O, Gaughan L, Downey C, et al. An interdisciplinary approach to improve surgical antimicrobial prophylaxis. Int J Health Care Qual Assur 2018;31:162-72.

31 Connor LO. Developing 'subject matter experts': an improvement methodology programme for acute postoperative pain with patients post major surgery. J Clin Nurs 2016;25:2629-38. 
32 Creed M, McGuirk M, Buckley R, et al. Using lean six sigma to improve controlled drug processes and release nursing time. J Nurs Care Qual 2019;34:236-41.

33 Davies $\mathrm{C}$, Lyons $\mathrm{C}$, Whyte $\mathrm{R}$. Optimizing nursing time in a day care unit: quality improvement using lean six sigma methodology. Int $J$ Qual Health Care 2019;31:22-8.

34 Dolan L, Kane M, Timmins F, et al. A hospital recreation room quality improvement intervention. Int J Health Care Qual Assur 2019;32:731-8.

35 Dymond M, O'Dochartaigh D, Douma MJ. Insights from a tertiary care intraosseous insertion practice improvement registry: a 2-year descriptive analysis. J Emerg Nurs 2019;45:155-60.

36 HSE Quality Improvement Divsion. Quality and safety walk-rounds: a co-designed approach: toolkit and case study report. Ireland, 2016. Available: https://www.hse.ie/eng/about/who/qid/governancequality/ qswalkrounds/quality-and-safety-walk-rounds-a-co-designedapproach-toolkit-and-case-study-report.pdf [Accessed 7 Dec 2020].

37 HSE Quality Improvement Divison. Final report pressure ulcers to zero collaborative phase 3 November 2016 - February 2018, 2018. Available: https://www.hse.ie/eng/about/who/qid/nationalsafetypr ogrammes/pressureulcerszero/final-report-putz-2018.pdf [Accessed 7 Dec 2020]

38 HSE Quality Improvement Division. Board on board with quality of clinical care': quality improvement project: case study report, 2015. Available: https://www.hse.ie/eng/about/who/qid/governancequality/ boardquality/hseboardonboard.pdf [Accessed 7 Dec 2020].

39 Irwin R, Abela GP, Stanescu S, et al. Managing opioid consumption after caesarean delivery: a quality improvement initiative. Ir J Med Sci 2020;189:1069-72.

40 Kieran M, Cleary M, De Brún A, et al. Supply and demand: application of lean six sigma methods to improve drug round efficiency and release nursing time. Int J Qual Health Care 2017;29:803-9.

41 Kilonzo I, Lucey M, Twomey F. Implementing outcome measures within an enhanced palliative care day care model. J Pain Symptom Manage 2015;50:419-23.

42 Lagan NC, Mc Grane F, Huggard D, et al. Implementation of a health surveillance clinic for children with Down syndrome. Arch Dis Child Educ Pract Ed 2021;106:60-2.

43 Linehan E, Brennan M, O'Rourke S, et al. Impact of introduction of Xpert flu assay for influenza PCR testing on obstetric patients: a quality improvement project. J Matern Fetal Neonatal Med 2018;31:1016-20.

44 McCarthy KN, Hawke A, Dempsey EM. Antimicrobial stewardship in the neonatal unit reduces antibiotic exposure. Acta Paediatr 2018;107:1716-21.

45 McGlacken-Byrne SM, O’Neill R, Jenkinson A. Continuous glucose monitoring in the management of neonatal hypoglycaemia. Ir Med J 2019;112:897.

46 McGrath K, Cunningham N, Moloney E, et al. Enhancing acute stroke services: a quality improvement project. BMJ Open Qual 2018;7:e000258.

47 McGrath K, Casserly M, O'mara F, et al. Zap it track it: the application of lean six sigma methods to improve the screening system of low-grade mucinous neoplasms of the appendix in an acute hospital setting. Int J Qual Health Care 2019;31:35-44.

48 McNamara DA, Rafferty P, Fitzpatrick F. An improvement model to optimise Hospital interdisciplinary learning. Int $J$ Health Care Qual Assur 2016;29:550-8.

49 Medani SA, Hensey M, Caples N, et al. Accuracy in precordial ECG lead placement: improving performance through a peer-led educational intervention. J Electrocardiol 2018;51:50-4.

50 Meehan D, Balhareth A, Gnanamoorthy M, et al. Efficacy of physician associate delivered virtual outpatient clinic. Int J Health Care Qual Assur 2019;32:1072-80.

51 Moran P, Barr D, Holmes C. Saving sevoflurane: automated gas control can reduce consumption of anesthetic vapor by one-third in pediatric anesthesia. Paediatr Anaesth 2019;29:310-4.

52 Moran PJ, Fennessy P, Johnson MZ. Establishing a new national standard for the documentation of regional anaesthesia in Ireland. BMJ Open Qual 2017;6:e000210.

53 Murphy L, Wells JS, Lachman P. A quality improvement initiative in community mental health in the Republic of Ireland. Health Science Journal2015;9:1.
54 Murray K, Low C, O'Rourke A, et al. A quality improvement intervention failed to significantly increase pneumococcal and influenza vaccination rates in immunosuppressed inflammatory arthritis patients. Clin Rheumatol 2020;39:747-54.

55 O'Hanlon M, McKenna C, Carton E. A quality improvement approach to reducing the caesarean section surgical site infection rate in a regional hospital. Ir Med J 2016;109:450.

56 O'Reilly O, Cianci F, Casey A, et al. National Acute Medicine Programme--improving the care of all medical patients in Ireland. $J$ Hosp Med 2015;10:794-8.

57 Osuafor CN, Enduluri SL, Travers E, et al. Preventing and managing constipation in older inpatients. Int J Health Care Qual Assur 2018;31:415-9.

58 Owen J, Conway R, Silke B. Medical record documentation among interns: a prospective quality improvement study. Ir Med J 2015;108:183-5.

59 Owens P, McHugh S, Clarke-Moloney M, et al. Improving surgical site infection prevention practices through a multifaceted educational intervention. Ir Med J 2015;108:78-81.

60 Riordan F, McHugh SM, Harkins V, et al. Sustaining quality in the community: trends in the performance of a structured diabetes care programme in primary care over 16 years. Diabet Med 2018;35:1078-86.

61 Ryan P, McGrath C, Lawrie I. Enhancing efficiency in a cardiac investigations department by increasing remote patient monitoring. Int J Qual Health Care 2019:3129-34.

62 Stewart K, Doody O, Bailey M, et al. Improving the quality of nursing documentation in a palliative care setting: a quality improvement initiative. Int J Palliat Nurs 2017;23:577-85.

63 Teeling SP, Coetzee H, Phillips M, et al. Reducing risk of development or exacerbation of nutritional deficits by optimizing patient access to mealtime assistance. Int J Qual Health Care 2019;31:6-13.

64 Ullah MF, Fleming C, Fox C, et al. Patient experience in a surgical assessment unit following a closed-loop audit using a Kaizen lean system. Ir J Med Sci 2020;189:641-7.

65 White M, Butterworth T, Wells JSG. Productive ward: releasing time to care, or capacity for compassion: results from a longitudinal study of the quality improvement initiative. J Res Nurs 2017;22:91-109.

66 White M, Butterworth T, Wells JSG. Healthcare Quality Improvement and 'work engagement'; concluding results from a national, longitudinal, cross-sectional study of the 'Productive Ward-Releasing Time to Care' Programme. BMC Health Serv Res 2017;17:11.

67 Lachman P, Batalden P, Vanhaecht K. A multidimensional quality model: an opportunity for patients, their kin, healthcare providers and professionals to coproduce health. F1000Res 2020;9:1140.

68 Cattacin S. Standards for equity in healthcare provision and utilisaton: pilot test in sixteen countries. Divers Equal Health Care 2020;17:115-24.

69 Slawomirski L, Auraaen A, Klazinga NS. The economics of patient safety: strengthening a value-based approach to reducing patient harm at national level. OECD Health Working Papers 2017.

70 Auraaen A, Slawomirski L, Klazinga N. The economics of patient safety in primary and ambulatory care: flying blind. OECD Health Working Papers 2018.

71 Kd B, Llena-Nozal A, Klazinga NS. The economics of patient safety Part III: long-term care: valuing safety for the long haul. OECD Health Working Papers 2020.

72 Dixon-Woods M, Martin GP. Does quality improvement improve quality? Future Hosp J 2016;3:191.

73 Hood VL, Weinberger SE. High value, cost-conscious care: an international imperative. Eur J Intern Med 2012;23:495-8.

74 Stammen LA, Stalmeijer RE, Paternotte E, et al. Training physicians to provide high-value, cost-conscious care: a systematic review. JAMA 2015;314:2384-400.

75 Owens DK, Qaseem A, Chou R, et al. High-Value, cost-conscious health care: concepts for clinicians to evaluate the benefits, harms, and costs of medical interventions. Ann Intern Med 2011;154:174-80.

76 Stammen L, Slootweg I, Stalmeijer R, et al. The struggle is real: how residents learn to provide high-value, cost-conscious care. Teach Learn Med 2019;31:402-11.

77 Burke S, Barry S, Siersbaek R, et al. Sláintecare - A ten-year plan to achieve universal healthcare in Ireland. Health Policy 2018;122:1278-82. 